\title{
Drug Eluting Bioresorbable Cellulose Acetate/PEO/HPMC Composite With Propolis Extracts for Suturing Application
}

\author{
Preethi Ramadoss ${ }^{1} \cdot$ Arivuoli Dakshanamoorthy ${ }^{1} \cdot$ Sabiha Hayath Basha ${ }^{2}$ \\ ${ }^{1}$ Crystal Growth Centre, Anna University, Chennai, Tamilnadu, India. \\ ${ }^{2}$ Centre for Stem Cell Research and Regenerative Medicine, Madras Veterinary College, Chennai, Tamilnadu, India.
}

\begin{abstract}
A detailed study on a drug eluting cellulose based resorbable suture material, elaborately characterized for its mechanical and physico-chemical properties is presented. The biocompatibility of the material was tested with 3T3 [NIH] cells. The material's ability to be heat sterilized has been verified with thermogravimetric analysis which exhibited stability up to $200^{\circ} \mathrm{C}$. Drug eluting property of the material loaded with propolis and without propolis has been assessed and the corresponding kinetics was determined. The material with propolis has shown a sustained drug release property of up to $56.96 \%$ in 72 hours following Zero-order kinetics. For an ideal suture material, blood clotting on the surface of the material could lead to serious complications, the synthesized cellulose composite materials have shown anti-thrombogenic property. The cellulose composite material with propolis incorporation has shown superior properties in mechanical strength, thermal stability, drug release, biocompatibility, surface wettability, anti-microbial and thrombus formation characteristics which is ideal for suture application. The composite material showed favorable morphological and mechanical changes during various stages of in-vitro degradation in DMEM.

(c) 2021 JMSSE · INSCIENCEIN. All rights reserved
\end{abstract}

ARTICLE HISTORY

Received 23-06-2021

Revised 28-07-2021

Accepted 29-07-2021

Published 21-10-2021

\section{KEYWORDS}

Cellulose Acetate Suture Material

Drug Release

Anti-Microbial

Anti-Thrombogenic

Propolis Loaded

\section{Introduction}

Suture materials for surgical use are the first ever known implants used in the history [1]. Among the biomaterials used in the implants suture materials constitute to a major market exceeding $\$ 1.3$ billion per annum [2]. Physicians have been using sutures for approximately 4000 years [1]. Archaeological records of Egypt and India show the use of linen, animal sinew, flax, hair, grass, cotton, silk, pig bristles, and animal gut to close wounds in ancient times[2]. Suture materials are either absorbable or nonabsorbable (Figure 1) made of either organic or synthetic materials. There are several materials being commercially used for surgeries in recent times. The popular materials used are viz., cotton, braided silk, catgut, nylon, polyester, polyglecaprone, polyglycolic acid and elongated polytetrafluoroethylene. Six clinical studies reported that braided silk elicited tissue inflammatory reaction [3-7]. An ideal suture should have the following characteristics [813]:

1. comfortable to handle

2. little to no tissue reaction

3. anti-microbial in nature

4. flexible

5. easily sterilized

6. non-allergenic

7. non-carcinogenic and

8. absorbable

Thus, a suture should not only be very strong but also be able to simply dissolve in body fluids and lose strength at the same rate as the tissue gains strength. It should neither cause nor promote complications. Thus, sutures should provide a secure wound approximation for an adequate time period with minimum to no interference on the normal wound healing process[14].

By 1900, catgut industry got notably established in Germany due to the demand for sausages grew at that time. Many methods of sterilizing were used but the introduction of iodine sterilization established by Claudius in 1902[15] had become the standard method of preparation for nearly half a century.

The introduction of steel wire and synthetic nonabsorbable fibers like nylon, polyester, and polypropylene were greatly becoming popular during World War II which in turn gave way for other synthetic materials to be used in surgeries. In the year 1906 first truly sterile catgut, sterilized by sporicidal treatment with iodine suggested by a German surgeon Franz Kuhn and Braun was developed. From 1908 onwards catgut and silk dominated the suture market until 1930 [16].

The task of selecting the right suture material is complicated due to the wide variety of suturing materials that are available. Selection of inappropriate sutures may increase the risk of complications thereby delaying the healing process [17]. When a wound reaches its maximum strength, there will be no need for sutures; therefore, for slow-healing tissues like skin, fascia, and tendons it will be better to choose non-absorbable sutures or long-lasting absorbable sutures. Whereas for close and fast healing tissues like stomach, colon, and bladder absorbable sutures are preferred. It is said that for potentially contaminated wounds monofilament suture materials should be used because multifilament suture materials don't cause infection, hence an anti-microbial suture material is preferred for contaminated wounds.

Suture manufacturing is regulated by the Food and Drug Administration [FDA] because sutures are classified as 
medical devices[18]. There are three classes of sutures viz., collagen, and synthetic absorbable, and non-absorbable. They are as classified as follows:

Class I - Silk or synthetic fibers of monofilament [twisted or braided]

Class II - Cotton or linen fibers or coated natural or synthetic fibers

Class III - Metal wire [monofilament or multifilament].

Sutures used for abdominal surgery are different from that of cataract surgery. Because not one type of suture material can be applicable for all types of surgeries. One may be more absorbable but less flexible, while another may be exceedingly strong but difficult to knot. The rate at which the suture material degrades is important, not only along the length of the suture but also at the knot.

The healing of wounds is a complex and dynamic process that can be separated into three phases[18].

Phase I- Inflammation: an inflammatory response for about 1-5 days occur where tissue exudates are seen along with increased blood supply and fibroblast proliferation.

Phase II- Collagen formation: covering a period of about 5-14 days, there is an increase in collagen formation together with formation of fibrin and fibronectin through fibroblastic activity followed by wound closure/contraction.

Phase III- Formation of connective tissues: from day 14 onward there is reorganization and maturation of collagen fibers together with deposition of fibrous connective tissues that result in scar formation.

This healing process occurs when there is no onset of infection, minimal edema [swelling], or fluid discharge. Complications in wound healing and delays commonly occur due to two primary reasons i. e., infection and mechanical effects[18].

Catgut and regenerated collagen are widely used absorbable natural sutures available in the market right now [18]. Catgut was the only available absorbable suture material through the 1930s. Catgut sutures are well known for their great toughness and tenacity. Catgut sutures are packed in alcohol solutions [ethanol or isopropanol] so as to retain their flexibility and packages are subsequently sterilized by either $\gamma$-irradiation or ethylene oxide [EO] treatment. Whereas, glycerin coated catguts [Softgut] eliminate the need of alcohol packing. The coating also improves handling characteristics[19]. Studies indicate that catgut sutures completely degrade within the tissue between 35 and 60 days[20]. However, Catgut is phased out in many countries, because the risk of CreutzfeldtJakob Disease [CJD] infection is still on the higher end when compared to the modern synthetic suture materials, even with improved sterilization processes[2].

Silk and cotton are non-absorbable sutures that have found to cause bacterial infections in 10 out of 11 patients when used for oral surgeries[4]. Especially with braided silk there's notable increase in the risk of bacterial infection when compared to other synthetic suture materials such as polyester, nylon, etc. Among the natural materials, chitin has been found to be a good candidate for sutures due to its immense flexibility, antimicrobial property, biodegradability and biocompatibility. Chitin is known to degrade within 4 months[1]. Other commercially available suture materials are classified (Figure 1) as follows:

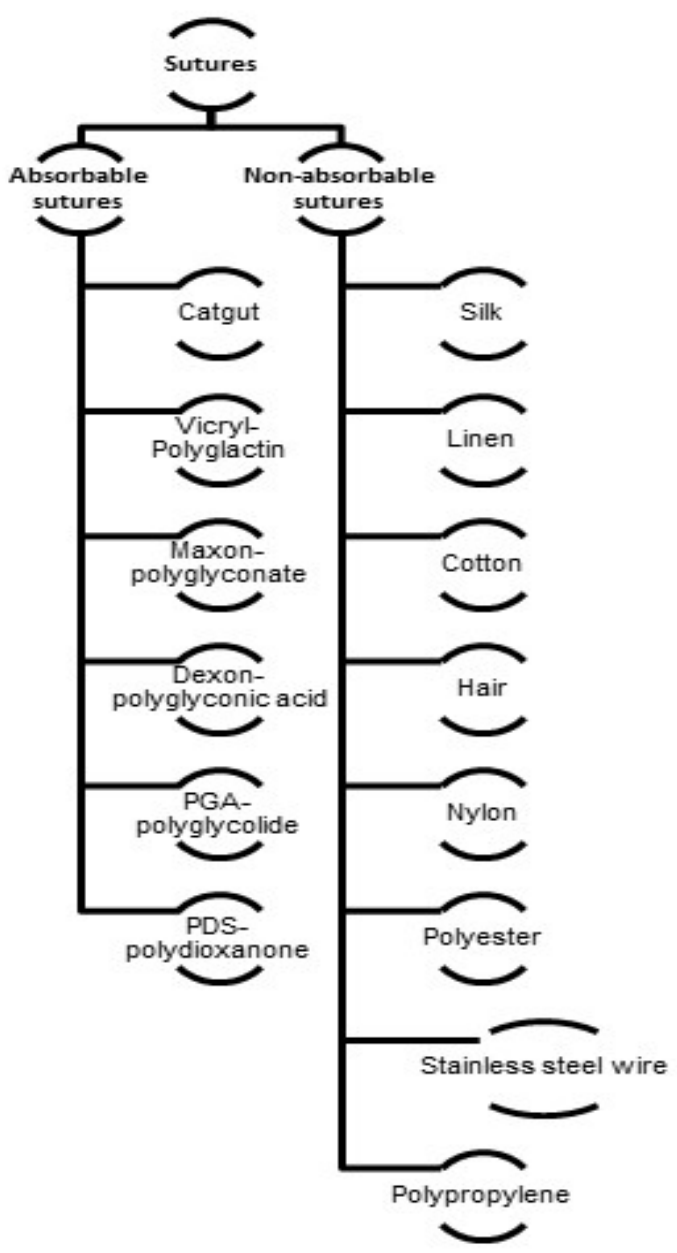

Figure 1: Types of absorbable and non-absorbable sutures

Cellulose acetate is an acetate ester of cellulose [a natural polymer] which is known for its good mechanical strength and flexibility. It was used in photographic films in 1980's. This material has been explored in the field of biomedical as tissue engineering scaffolds and drug delivery devices[21-22]. Catgut, silk and chitin are animal derivatives that involve animal cruelty for the production.

Hence a naturally occurring polymer is chosen for this study which is known for its biocompatible, biodegradable, non-toxic and non-irritant properties. The present investigation elaborates on the use of cellulose acetate as a potential candidate for suture material by studying its thermal stability, mechanical strength, oxygen permeability, heat sterilizability, drug delivery property and biocompatibility with 3T3 fibroblast cells. Propolis extracts are added to the materials for imparting antibacterial property [23-24]. Propolis is a resin secreted by the honey bees to protect their hive from other predatory insects. It is a potent antimicrobial agent which is predominantly composed of naphthalene, decanoic acid and azulene [anti-inflammatory compound][23].Bayger T et. al [24] have studied the properties of silk sutures coated with propolis and biogenic silver NPs for wound healing efficiency at the surgery site. 


\section{Experimental}

Cellulose acetate was procured from Pallav chemicals, Polyethylene oxide [MW: 1,00,000] and Hydroxypropyl methyl cellulose [HPMC] was procured from Sigma Aldrich and Bangalore fine chemicals respectively. Triacetin [Glycerol triacetate] procured from SRL chemicals, diethyl was procured from LobaChemie and Methoxyethanol procured from SRL chemicals was used as the solvent. Bee Propolis was procured from Hi-Tech Naturals, Delhi, India. $2 \mathrm{~g}$ of cellulose acetate, $10 \%$ HPMC and $20 \% \mathrm{w} / \mathrm{w}$ of PEO was taken and dissolved in $40 \mathrm{ml}$ of methoxyethanol and $10 \mathrm{ml}$ of ethanol at $60^{\circ} \mathrm{C}$ for 4 hours until it becomes completely homogenous and $0.4 \% \mathrm{v} / \mathrm{v}$ of diethyl phthalate along with $1.4 \% \mathrm{v} / \mathrm{v}$ of triacetin is added when the solution cools down to room temperature and is allowed to stir for another 2 hours. For propolis loaded material 12\% v/v of ethanol extracted propolis is added to the mixture. After 6 hours of stirring the cellulose composite mixture is poured onto glass petriplates and dried at $55^{\circ} \mathrm{C}$ for 48 hours. The films are then peeled and stored in vacuum containers for further characterization.

UV spectrophotometer [JASCO V-760] was used for the UV measurements. The SEM images were taken with the help of Carl Zeiss MA 15/EVO 18 Microscope in Chennai, India. Prior to taking SEM images the samples were coated with gold by sputtering technique. AFM was taken with the help of Park XE-100 Atomic Force Microscope.Folding endurance ASTM standard [D-2176] is a standardized experiment usually performed for plastic or paper films in industries. Folding endurance is a logarithm of number of double folds required to break a film in standardized conditions. It is performed with the help of a folding endurance tester under normal room temperature conditions. For the cellulose composite material, the test was performed with $200 \mathrm{~g}$ of load applied on the material and folded until break. Nanoindentation analysis was performed using Triboindenter TI-950 with the help of a Berkovich tip of radius $100 \mathrm{~nm}$. The test was performed at three different locations on the cellulose composite material. Fourier transform infrared spectrometer was performed using Jasco International FTIR-6300.All the analyses were done in Chennai, India.

\section{Results and Discussion \\ Atomic Force Microscopy Analysis}

The synthesized composite materials were analyzed using the atomic force microscope [AFM] to determine the surface roughness. The surface roughness of the material without propolis was said to be $5.9 \mathrm{~nm}$ whereas for the one with propolis it has increased up to $30.6 \mathrm{~nm}$. The surface roughness plays an important role in reducing the friction between the suture material and the tissue. In order to avoid any tissue friction, it is better to have a lower surface roughness as shown in Figure 2. Hydrophobic polymers usually tend to have lower surface roughness. Surface roughness may also indicate that the material is porous. And a higher surface roughness facilitates better cell adhesion. Cell adhesion plays an important role in life systems by communicating, regulating and organ/tissue formation in every life system. Nano-roughness of a substrate is said to be the closest morphology of extracellular matrix [ECM] that is ideal for cell adhesion, maturation and growth [25].

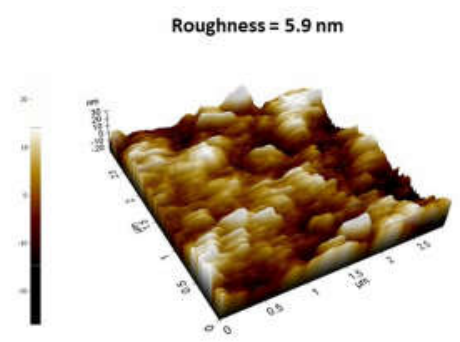

(a)

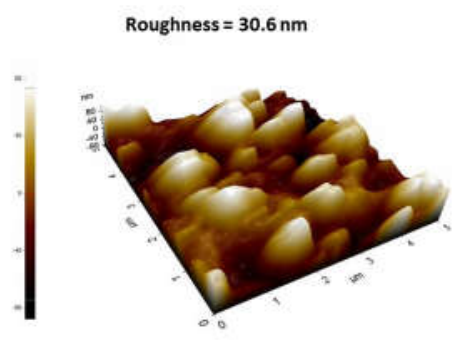

(b)
Figure 2: AFM images of the cellulose composite material [a] without propolis extracts [roughness $=5.9 \mathrm{~nm}$ ] and [b] with propolis extracts [roughness $=30.6 \mathrm{~nm}$ ]

\section{Fourier-Transform Infrared Spectroscopy Studies}

The peak at $3422 \mathrm{~cm}^{-1}$ corresponds to the $0-\mathrm{H}$ stretching of the cellulose acetate and HPMC [Figure 3]. The short peak at $2902 \mathrm{~cm}^{-1}$ corresponds to the $\mathrm{C}-\mathrm{H}$ [alkane] stretching. The peak at $1731 \mathrm{~cm}^{-1}$ corresponds to the strong aldehyde $[\mathrm{C}=0]$ group present in cellulose acetate. The medium peak at $1372 \mathrm{~cm}^{-1}$ has arisen due to the presence of alcohol [$\mathrm{OH}]$ in the compound. The peak looks intensified for the material with propolis due to the additional content of $-\mathrm{OH}$ groups from phenolic compounds and the presence of 3ethylbenozothiazoline-6-sulfonate present in the propolis. The strong band at $1221 \mathrm{~cm}^{-1}$ is due to the presence of C-O groups in the cellulose acetate. The peak at $1032 \mathrm{~cm}^{-1}$ corresponds to the anhydride $[-\mathrm{C}=\mathrm{O}-\mathrm{O}-\mathrm{C}=\mathrm{O}-\mathrm{-}$ group that has occurred due to the reaction between glycerol triacetate, polyethylene oxide and cellulose acetate [26].

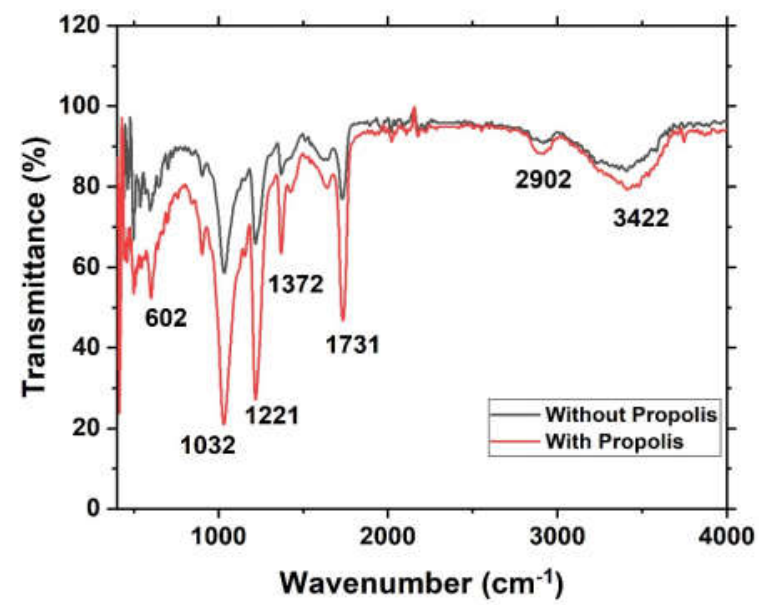

Figure 3: FTIR spectrum for the cellulose composite material with and without propolis

\section{Thermal Gravimetric Analysis}

Thermal gravimetric analysis showed that there was a very minimum of (nearly 20\%) weight loss observed from 100$140^{\circ} \mathrm{C}$ (Figure 4) which was the loss of water molecules that were bound to be the $-\mathrm{OH}$ groups of the cellulose acetate/polyethylene oxide/triacetin/diethyl phthalate compounds present in the sample. The second phase of degradation occurs from $200^{\circ} \mathrm{C}$ to $300^{\circ} \mathrm{C}$ which attributes to the breakage/decomposition of glycosidic bonds and thermal decomposition of the hemicelluloses thereby destroying the cellulose acetate chain. The third phase of decomposition occurs from $400^{\circ} \mathrm{C}$ up to $500^{\circ} \mathrm{C}$ which is the complete decomposition/carbonization of the material [27]. 


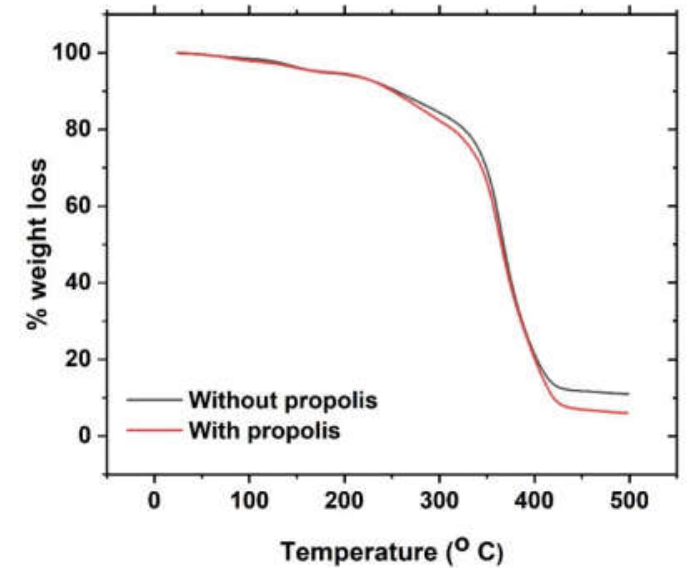

Figure 4: TGA curve for the cellulose composite materials with and without propolis

According to the sterilization protocols, steam sterilization is the most inexpensive technique used in hospitals to sterilize all the surgical equipment prior to the surgery. Similarly, for suture materials too, sterilization has been recommended by Joseph Lister [28]. Hence, the standard sterilization process for suture materials has been to soak the material in $10 \%$ povidone solution for at least 10 minutes or sterilize it with ethylene oxide [EO]. However, it varies with the different types of suture materials used. The standard steam sterilization technique follows a method of heating the material up to $121^{\circ} \mathrm{C}$ for at least 30 minutes to kill the microorganisms present in the material. Hence the suture material should be able to withstand this temperature [29]. The synthesized cellulose acetate film is said to withstand this temperature without getting deformed. This property of the material could be due to the presence of the hydrophobic acetate units in the cellulose structure and the crosslinker diethyl phthalate and glycerol triacetate in the material that makes the polymeric units tightly linked to each other.

There is not much difference in the thermal decomposition profiles for the composite material with and without propolis extracts in them, it only indicates that the material could withstand sterilization temperatures.

\section{Anti-Bacterial Assay}

Anti-bacterial properties of the materials were tested and compared by doing agar diffusion assays of the materials incorporated with antibiotic and the materials without anti-biotic incorporation. The zone of inhibition was measured against two species s. aureus [gram-positive] and p. aeruginosa [gram-negative]. Nutrient agar was used for performing this experiment and all the measurements were done in triplicates. The plates were incubated at $37^{\circ} \mathrm{C}$ for 24 hours before taking the images (Figure 5) and measuring the zone of inhibition. Gram-negative bacterium has a cell membrane that contains lipid bilayer which is difficult to break when compared to the thicker cell membrane that the gram-positive bacterium. A lipophilic compound such as azulene, naphthalene and pentadecanoic acid present in the ethanol extracts of the propolis[23] could eventually make its way through the cell membrane of the gram-negative bacteria there by giving better zone of inhibition when compared to the material without propolis extracts. The presence of lipophilic aromatic rings in the propolis extracts has given rise to the antibacterial property (Figure 5). Honey bees use propolis to seal their hives from other predatory insects; hence the presence of naphthalene is copious [7.89\%] in it.
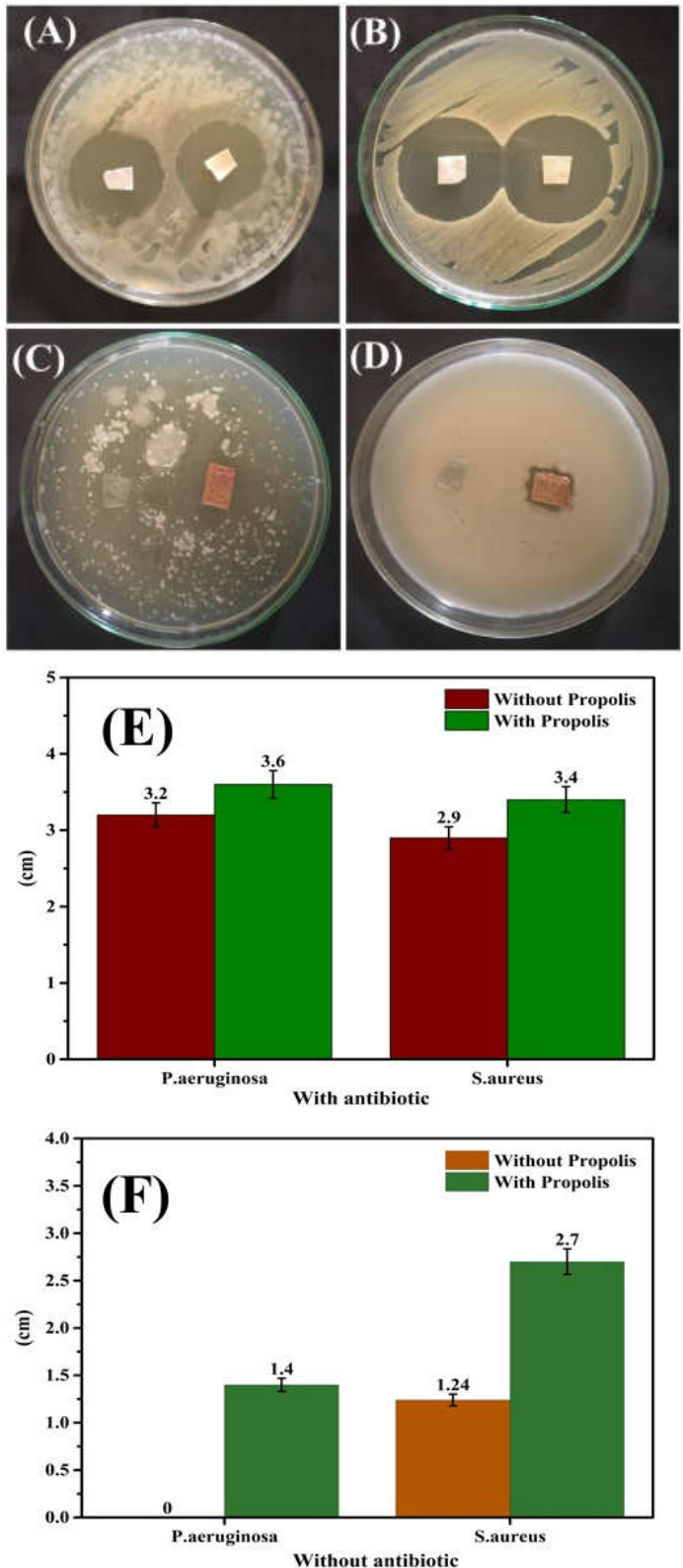

Figure 5: Antibacterial assay of the cellulose composite materials with and without propolis extracts for [a] s. aureus with antibiotic [b] p. aeruginosa with antibiotic [c] s. aureus without antibiotic [d] p. aeruginosa without antibiotic [e] the zone of inhibition in $\mathrm{cm}$ for the samples with antibiotic [f] the zone of inhibition in $\mathrm{cm}$ for the samples without antibiotic

The materials that were loaded with gentamycin $(75 \mathrm{mg} / 3 \mathrm{~g}$ of the sample) (antibiotic) (Figure $5 \mathrm{a}, \mathrm{b} \& \mathrm{e}$ ) showed better zone of inhibition when compared to the composites without gentamycin (Figure 5 c, d \& f). Suture materials should possess antimicrobial property in order to prevent infections. Especially the resorbable suture materials should be resistant to bacterial infections due to the fact that it stays for a longer time with the tissues at the injured site.

\section{Oxygen Permeability}

Oxygen permeability is very important requirement for any implant material because there is a constant exchange of 
oxygen between the cells that come in contact, adhere and grow on the substrate. The rate of wound healing rapidly increases in oxygen permeable atmosphere. The cellulose composite materials with and without propolis incorporation have shown good amount of oxygen permeability (Figure 6) which makes them suitable for implantable material too. Oxygen permeability of the material depends on the material's density and crystallinity of the matrix. The higher the density and the crystallinity the lesser is the oxygen permeability.

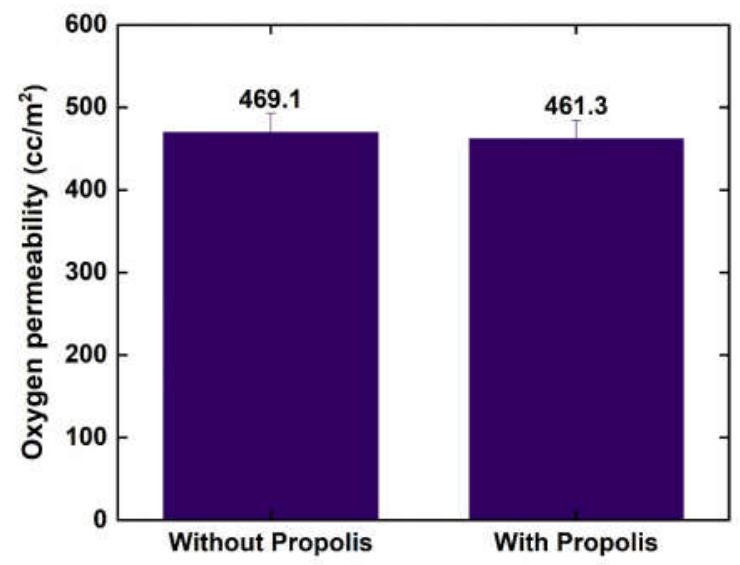

Figure 6: Oxygen permeability of the cellulose composite materials

\section{Contact Angle}

Although cellulose acetate is water insoluble [hydrophobic] the synthesized composite material has an ideal wettability in such a way that it can reduce the friction between the tissue and the suture material. Lubrication of any implantable material is important to avoid any kind of tissue irritation and inflammation. The contact angle measurements of the synthesized cellulose acetate composite material showed a very intermediate behavior between hydrophilic and hydrophobic nature (Figure 7).
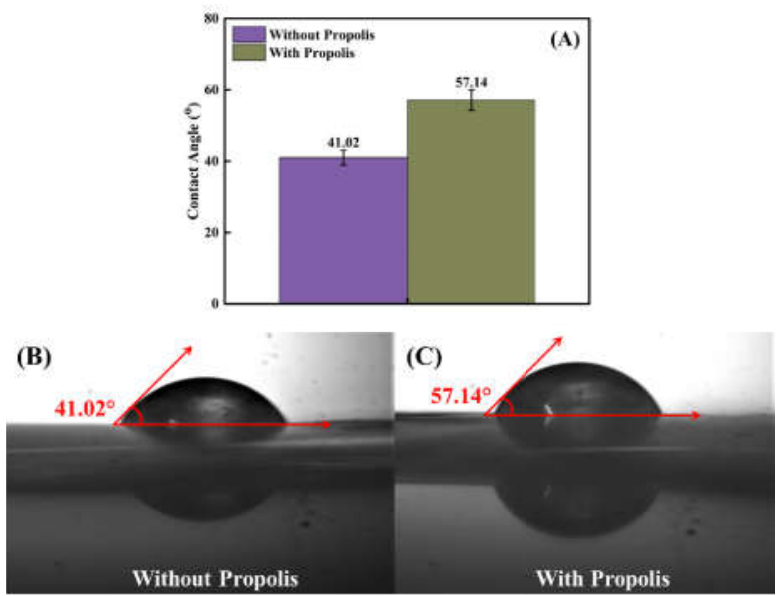

Figure 7: (a) Contact angle measurements for the cellulose composite materials and the images showing the water contact angle on the surface of the cellulose composite materials,

(b) without propolis extracts [c] with propolis extracts Gangqiang Zhang et al. [2020][30] studied the effects of coating dopamine and carboxymethyl chitosan on surgical suture materials to study the frictional performance of the suture materials by sliding it through skin substitutes. The study showed that reducing the surface contact angle down to $55^{\circ}-60^{\circ}$ makes it better fitted for application in skin injuries.

The cellulose composite without propolis extracts (Figure 7a) shows a contact angle of $41.02 \pm 2^{\circ}$ which is quite hydrophilic due to the presence of hydrophilic components such as polyethylene oxide and glycerol triacetate. However, the introduction of propolis extracts (Figure 7c) has greatly increased the surface hydrophobicity of the material to $57.14 \pm 2.8^{\circ}$ thereby making the material more suitable for the purpose. The increase in hydrophobicity has occurred due to the presence of lipophilic compounds present in the propolis extracts such as pentadeconoic acid, azulene, naphthalene, etc., which are predominantly made of aromatic benzene rings that are non-polar and insoluble in water [31].

\section{Hemolysis}

Hemolysis refers to the condition where the red blood cells get ruptured when it comes into contact with a foreign material which leads to the release of the cell contents into the blood plasma. This happens when the material is not biocompatible or particularly hemocompatible. In order to test synthesized cellulose composite materials' hemocompatibility properties the materials were subjected to hemolysis experiment. $0.3 \mathrm{~g}$ of the materials was stabilized at $37^{\circ} \mathrm{C}$ in PBS for 24 hours prior to the experiments [the experiment was performed in triplicates]. After 24 hours $1 \mathrm{ml}$ of human blood was added to the materials and incubated at $37^{\circ} \mathrm{C}$ for 20 minutes, following which $2 \mathrm{ml}$ of PBS was added to stop the lysis and allowed to incubate for 1 hour. The samples were then centrifuged at 1000 RPM for 10 minutes and the supernatant was observed at $545 \mathrm{~nm}$ under UV-Vis spectroscopy. The O. D values at $545 \mathrm{~nm}$ for both the samples were then substituted in the following formula [32] for calculating the percentage of hemolysis that has occurred when in contact with the material.

$$
\% \text { Hemolysis }=\frac{O . D \text { of the test sample }-O . D \text { of the negative control }}{O . D \text { of the positive control }-O . D \text { of the negative control }}
$$

Where,

Negative control- $P B S$

Positive control- $1 \mathrm{ml}$ of blood diluted with $2 \mathrm{ml}$ of distilled water

The results showed that material is completely hemocompatible with very negligible percentage of lysis (Figure 8). Sunitha, et. al. [33] have worked on coating suture material with curcumin pegylated gold nano particles [CGNPs] in order to reduce the hemolytic effect of the materials, they achieved $0.8 \%$ hemolysis after coating the material with CGNPs.

In the present work, the material showed $0.9 \pm 0.04 \%$ of hemolysis without propolis and with propolis it has further reduced to $0.6 \pm 0.03 \%$.It was compared with the control [blood without material] and the control sample's hemolysis was found to be $0.97 \pm 0.05 \%$ which was higher than the blood samples incubated with cellulose composite materials. This shows that the material is very hemocompatible and best suited for suture applications because if the material causes hemolysis, then the blood cells interaction with the material will reduce which in turn will delay the wound healing mechanism due to lower oxygen supply and cell adhesion on the surface of the suture that may lead to infection at the site. The biodegradability of the suture also depends on the surfacecell adhesion and proliferation. 


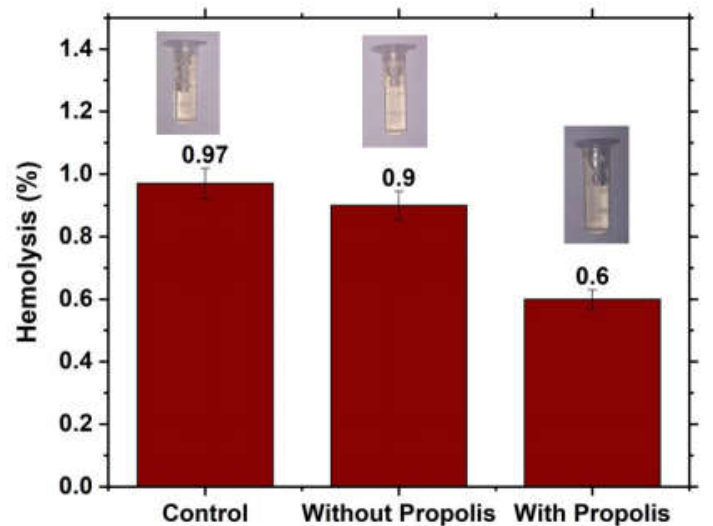

Figure 8: Blood compatibility measurements for the cellulose composite materials

\section{Thrombus Formation}

The suture material is said to have the lowest thrombogenicity in order to reduce the infection. Thrombogenicity refers to the formation of blood clot at the injury site with the contact of the suture material. Less thrombogenic material is preferred for cardiac and vascular suturing. Hence the cellulose composite materials were analyzed for their thrombogenic property as follows: $0.3 \mathrm{~g}$ of the material was stabilized in PBS at $37^{\circ} \mathrm{C}$ for 24 hours [all experiments were performed in triplicates]. The PBS solution was drained and the samples were air dried for few minutes, the materials [without propolis, with propolis and glass substrate] were weighed using a weighing scale [initial weight]. $50 \mu \mathrm{L}$ of human blood was placed on the samples; a glass substrate was also used as the control [34]. The human blood was allowed to clot by adding $30 \mu \mathrm{L}$ of $4 \mathrm{M} \mathrm{CaCl}_{2}$, the clot was subsequently fixed with $2 \%$ glutaraldehyde for 15-20 minutes. After which the materials [without propolis, with propolis and glass substrate] was washed with deionised water and allowed to dry at $40^{\circ} \mathrm{C}$ for a few minutes before taking the final weight. The final weight of the clot was determined by the difference obtained between the respective sample's initial weight and final weight. The weight of the clot was compared to the weight of the clot on the glass substrate and it was found to be $0.322 \pm 0.01 \mathrm{~g}, 0.055 \pm 0.003 \mathrm{~g}$ and $0.067 \pm 0.002 \mathrm{~g}$ for glass, without propolis and with propolis respectively (Figure 9). The materials were said to have very minimum thrombogenicity making it ideal for cardio-vascular surgeries.

\section{Mechanical Studies}

The samples were soaked for 1 hour in PBS solution prior to the tensile testing. The samples were tested in both dry and wet forms in order to assess its strength when used as suture material. A suture material is supposed to retain its strength until the cells start growing at the injured site. Besides retaining its strength, it is also supposed to withstand multiple stress given at the time of suturing, hence in its dry form it is supposed to be extremely flexible in order to enable stable knots.

When compared to the cellulose composite without propolis extracts the composite that is incorporated with propolis has shown better tensile properties as far as tensile stress and Young's modulus (Figure $10 \mathrm{a} \& \mathrm{~b}$ ) results are concerned. The incorporation of polyethylene oxide in cellulose acetate has given rise to higher tensile strength [35].

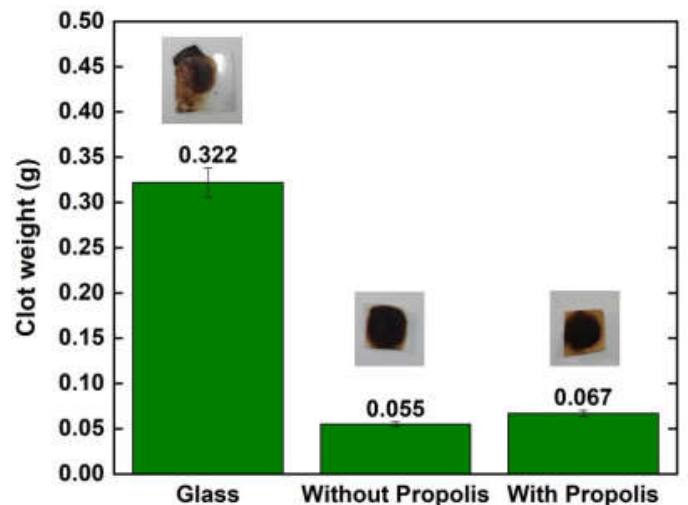

Figure 9: Thrombus formation profile of the cellulose composite materials compared with glass substrate
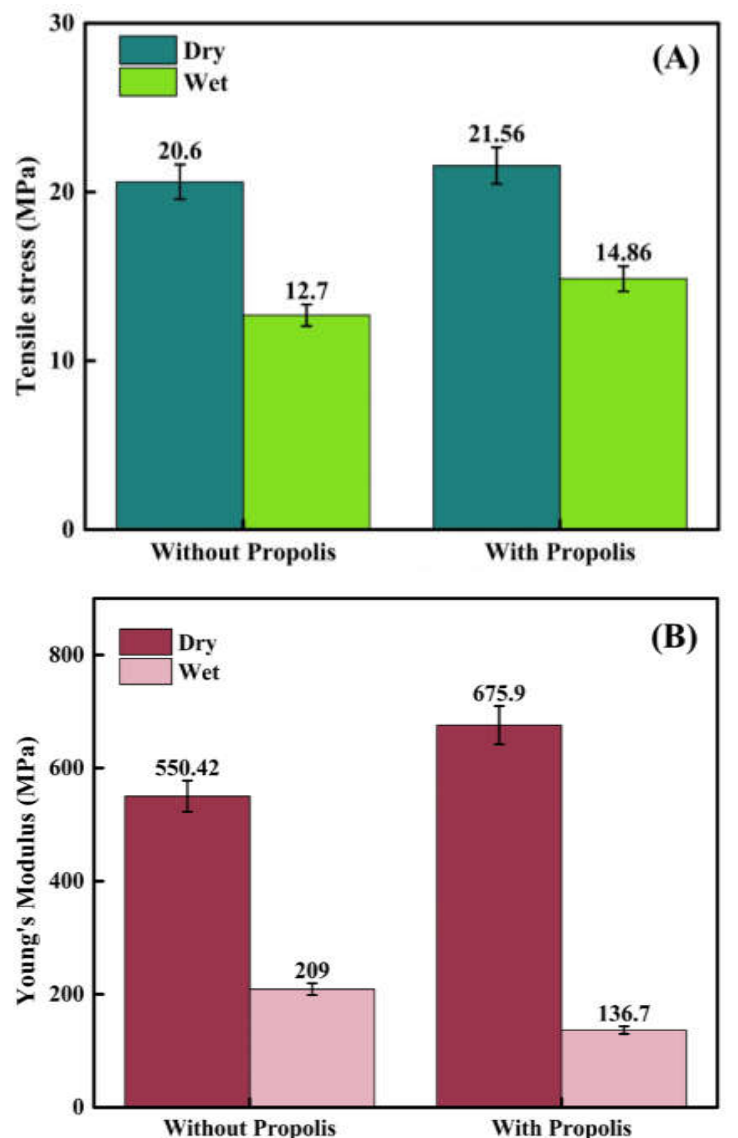

Figure 10: (a) Tensile stress of the cellulose composite materials

(b) Young's modulus of the cellulose composite materials

The cellulose composite materials were tested for their folding endurance as per ASTM standard D-2176. The material is folded number of times for 130 cycles per minute with a load of $200 \mathrm{~g}$ on it until it breaks. The material's strength and flexibility were determined by the number of cycles it could withstand until it breaks (Figure 11). In this case the material without propolis extracts could withstand 896 cycles whereas the cellulose composite with propolis breaks after 793 cycles. The material's flexibility could be attributed to the presence of plasticizers diethyl phthalate and triacetin. 


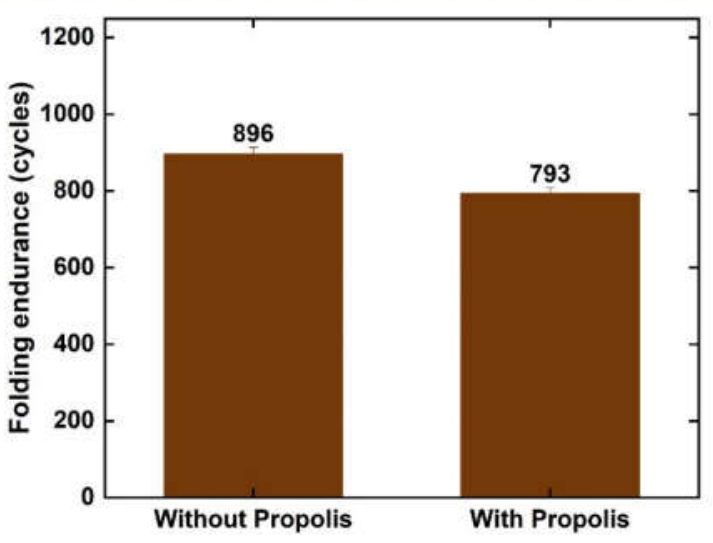

Figure 11: Folding endurance of the cellulose composite materials

\section{in-vitro degradation:}

The synthesized materials were subjected to in-vitro degradation procedure with the help of DMEM for 90 days and the samples were dried and weighed in regular time intervals to check the physical deterioration and their corresponding mechanical properties were also monitored for 30, 60 and 90 days so as to know the materials ability to retain its mechanical strength during the period of degradation. The percentage of degradation that was observed after 90 days in the material without propolis was $36.7 \pm 1.8 \%$ whereas for the material with propolis it is said to be $37.5 \pm 1.8 \%$.

The in-vitro DMEM degradation was carried out by initially weighing a piece of the sample and then placing them in a 6 well plate. $2 \mathrm{ml}$ of DMEM high-glucose is added to the samples and kept at $37^{\circ} \mathrm{C}$ while the medium is replenished every once in 3 days. The samples were then taken out at specific time intervals, dried at $40^{\circ} \mathrm{C}$ and weighed. The degree of degradation was calculated with the help of the following equation where $W_{0}$ is the initial weight of the sample and $W_{1}$ is the final weight of the sample[36]:

$$
\% \text { degradation }=\left(\frac{W_{0}-W_{1}}{W_{0}}\right) \times 100
$$

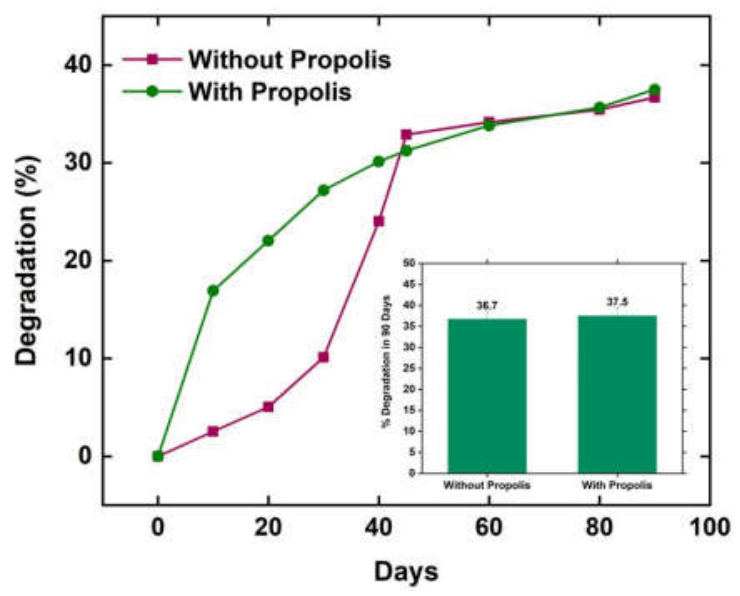

Figure 12: in-vitro degradation profile of the composite materials in DMEM

Cellulose acetate is a semi-synthetic polymer where the cellulose is partially esterified with acetic acid rendering it hydrophobic. Besides having surface hydrophobicity, the polymer is also found to be susceptible to degradation in aqueous solutions due to the presence of esters. Due to the presence of ester groups in the cellulose acetate structure it most easily gets attacked by $\mathrm{H}_{2} \mathrm{O}$ molecules by hydrolysis reaction thereby the degradation starts. The slow degradation is due to its surface hydrophobicity. However, Aikaterini-RafailiaTsiapla et.al., [2018][36] studied the DMEM degradation of electrospun matrix of pure cellulose acetate polymer loaded with dexamethasone drug and reported a degradation of $30.2 \%$ in a span of 150 days. In the present work we have shown that there is a degradation of up to $36.7 \pm 1.8 \%$ in 90 days (Figure 12). This could be attributed to the presence of more hydrophilic components and $\mathrm{OH}$ groups in the composite material such as polyethylene glycol and hydroxypropyl methyl cellulose. The slightly higher degradation rate of the propolis incorporated composite material could be associated with the combined action of organic salts such as calcium chloride, potassium chloride, magnesium sulfate, ferric nitrate, sodium chloride, sodium bicarbonate, sodium phosphate and the dextrose and other amino acids present in DMEM with the phenolic [aromatic rings] compounds present in the propolis extract which has accelerated the degradation process although the surface hydrophobicity of the material with propolis extracts is higher than that of the composite material without propolis extracts.

Nanoindentation was performed on the samples at various stages of degradation [0 day, 30 days, 60 days and 90 days]. $100 \mathrm{~nm}$ Berkovich diamond tip was used and the experiment was performed at displacement/depthcontrolled mode by keeping the depth limit to $50 \mathrm{~nm}$ and the corresponding load vs depth graph was obtained for both the set of samples [with and without propolis 0D,30D,60D,90D] (Figure 13 a \& b). In both the cases we could see a similar pattern in reduction of load as the duration of degradation increased like for example in Figure 14, we can see that the load it takes to reach $50 \mathrm{~nm}$ depth has significantly decreased for the samples taken after 90 days of degradation time. There is a gradual decrease in the amount of load required to reach the maximum depth which proves that the samples became softer as the

duration of degradation time increased. For the composite material incorporated with propolis we can see that the materials of day 60 and day 90 show a similar trend in load vs displacement curve indicating that the onset of degradation increases rapidly after day 60 .

The lesser the force required to reach a certain depth signifies that the sample is more elastic and subsequently less rigid. This was confirmed from the values of the hardness and reduced modulus obtained (Figure 13 c \& d). The loss of rigidity could be attributed to the loosening of the polymer chain due to the weight loss that has occurred by hydrolysis process in the polymer matrix as seen in the Figure 13c. As the glycosidic bonds of the cellulose acetate polymer breaks and the monomers disperse into the medium there is loss of solid components in the polymeric matrix that loosens the chains thereby making it less rigid and more elastic.

SEM images have been taken for the materials at various stages of degradation. In Figure 14 we can clearly see the surface morphological changes of the materials gradually from Day 0- Day 90. The as synthesized samples surface morphology for the material with and without propolis incorporation is shown on Day 0 images of Figure 14. 

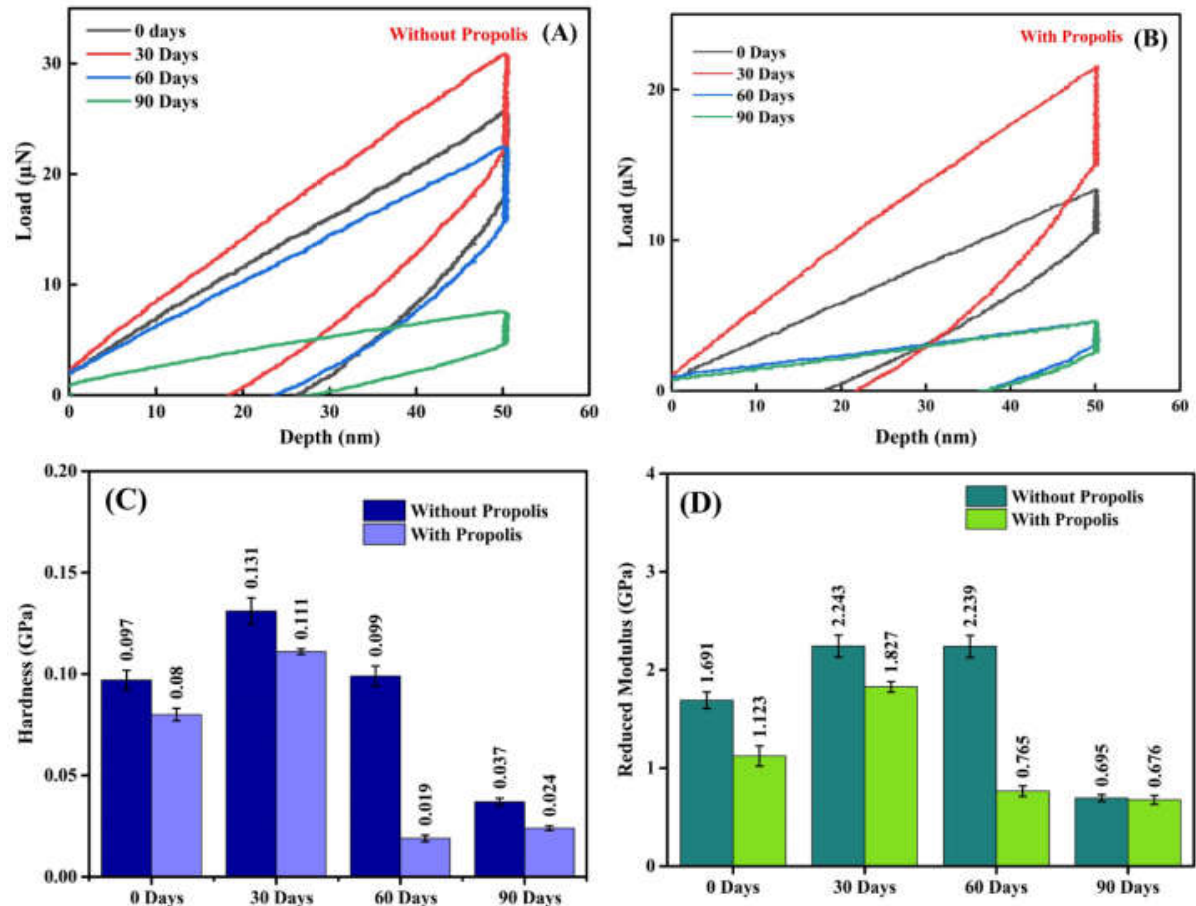

Figure 13: Nanomechanical properties of the cellulose composite material[a] without propolis and [b] with propolis at various stages of degradation. [c] Hardness values of samples with and without propolis at various stages of degradation [d] Reduced modulus values of samples with and without propolis at various stages of degradation
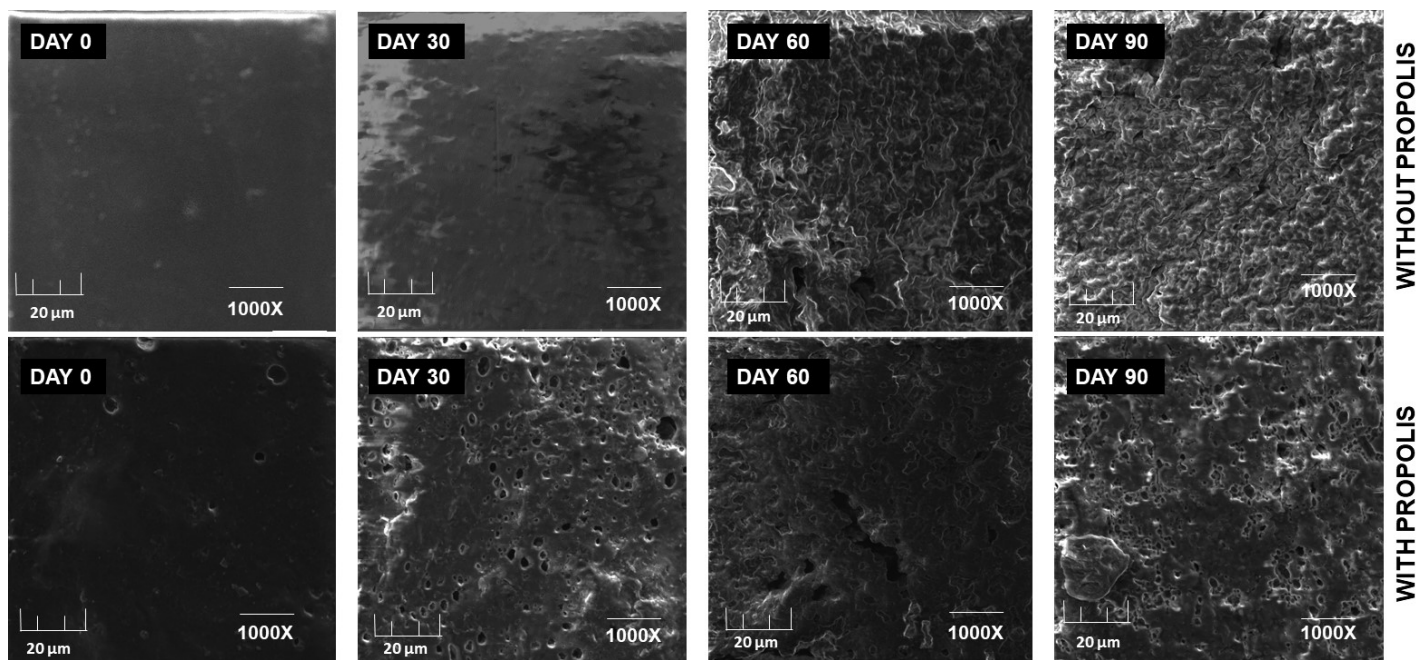

\section{$\frac{0}{1}$
0
0
0
0
0
5
$\frac{5}{1}$
$\frac{1}{3}$
3}

Figure 14: Surface morphology [SEM] of the cellulose composite materials with and without propolis

incorporation on Day 0, day 30, day 60 and day 90.

It can be seen that propolis incorporation has naturally formed a microporous nature on the material's surface which is said to have increased the surface roughness as seen in AFM image (Figure 2) thus enhancing cell adhesion [25]. As the days of degradation increases, we can see that the material becomes more porous. This is because of the loss of solid components of the polymeric matrix by the act of hydrolysis. On day 30 we can see the onset of pore formation on the material with propolis whereas for the material without propolis no change on the surface morphology was observed, hence it can be said that the addition of propolis has accelerated the degradation process. This is in compliance with the results obtained from mechanical properties of the material at various stages of degradation. We could see from the mechanical properties (Figure 13) that the elasticity of the material increased while the hardness gradually decreased. Hence it can be clearly seen that the elasticity increased because of the loosening of the polymeric chains thus forming a porous structure as seen in Figure 14.

\section{Drug Release}

Drug eluting suture materials can be used in order to prevent post-surgery infections[36]. Normally in braided sutures the infection rate is high. Especially with absorbable sutures there is a high risk of infection due to prolonged contact of the foreign material with the tissues. In 2002, for the first time triclosan coated polyglactin suture was approved by USA FDA. In 2014 antibiotic [levofloxacin] loaded PLA and Polyethylene glycol suture materials were used for ophthalmic surgeries[37]. Weldon et. al developed a PLGA suture that eluted anti- 
inflammatory drug called bupivacaine in 2012 [38]in order to produce local anesthetic effect on the site of injury[39].Aikaterini-Rafailia Tsiapla et. al [36] have studied the drug eluting properties of electrospun cellulose acetate fibres loaded with dexamethasone.

$3 \mathrm{~g}$ of each material incorporated with $75 \mathrm{mg}$ of diclofenac each was immersed in $100 \mathrm{ml}$ of saline solution and shaken at $100 \mathrm{RPM}$ at $37^{\circ} \mathrm{C}$ for 72 hours. At various intervals $2 \mathrm{ml}$ of the solution was withdrawn and UV absorption was taken at $295 \mathrm{~nm}$ wavelength. The solution was then replenished with fresh saline after every UV measurement. The O.D values were compared to the standard graph obtained with serial dilution of the diclofenac drug that was taken separately and the corresponding concentration was found using $\mathrm{y}=\mathrm{mx}+\mathrm{c}$ formula.

Prolonged drug release mechanism is warranted in order to prevent any post-operative complications. In this study we have used diclofenac as the model drug which is a nonsteroidal anti-inflammatory drug [NSAID]. The drug release profile was monitored for 72 hours and it was found that the cellulose composite material incorporated with propolis has made a huge difference in the percentage of drug released. Propolis extracts has helped in maintaining a sustained release pattern for the material as opposed to the material without propolis (Figure $15 \mathrm{a}$ ). The percentage of drug released for the cellulose composite without propolis in duration of 72 hours is $100 \%$, whereas the material with propolis has a sustained release of about $56.96 \pm 0.56 \%$ of the drug up to 72 hours (Figure $15 \mathrm{~b}$ ).
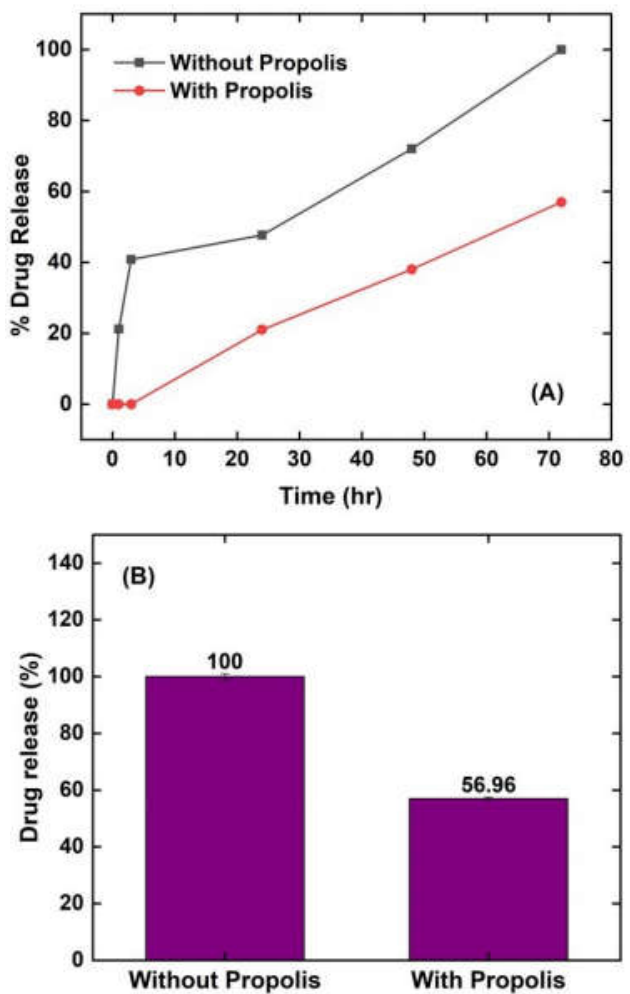

Figure 15: [a] Diclofenac drug release profile of the cellulose composite materials [b] Percentage drug release of the cellulose composite materials with and without propolis

Propolis extract has made the cellulose composite more hydrophobic by adding aromatic rings in the matrix thus restricting the wettability of the material more efficiently than the composite without propolis. Hence the water molecules that usually act as the carrier of the drug molecules to the medium could not penetrate the matrix. Also, it could be due to the fact that diclofenac drug being a lipophilic compound, it could've bonded with the aromatic rings present in the propolis extract, thus restricting the drug molecule to be released into the medium.

\section{Drug Release Kinetics}

The drug release patterns were correlated with the following models:

\section{Korsmeyer-Peppas model \\ Zero-order Kinetics \\ First-order Kinetics \\ Higuchi model}

The corresponding $\mathrm{R}^{2}$ values (Figure 16) were calculated using the appropriate formulae [40]. The closest kinetics model followed by the material without propolis is First Higuchi $\left[\mathrm{R}^{2}=0.9248\right]$, whereas the material with propolis follows Zero-order kinetics model $\left[\mathrm{R}^{2}=0.9969\right]$.

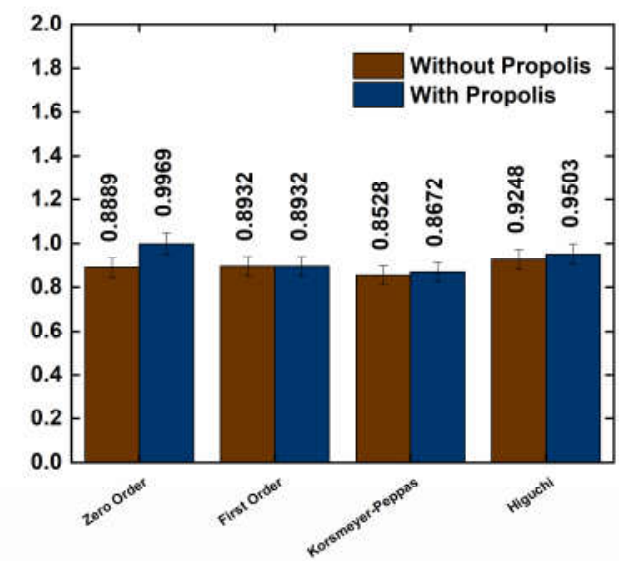

Figure 16: The Calculated $\mathrm{R}^{2}$ values corresponding to the drug kinetic models

\section{Cell Culture}

The synthesized cellulose composite material was tested for its biocompatibility nature with $3 \mathrm{~T} 3[\mathrm{NIH}]$ fibroblast cells. Confluent cells were seeded onto the materials on a 96-well plate under sterile conditions. The cells were grown in DMEM [high glucose] with 5\% filtered human blood serum [procured from blood bank]. The percentage of serum used was optimized with comparison to fetal bovine serum prior to this assay. The growth medium was replenished once in two days and was maintained at $37{ }^{\circ} \mathrm{C}$ with $5 \% \mathrm{CO}_{2}$ throughout. All experiments were performed in triplicates. It was found that the cells showed good proliferation on both the materials [with and without propolis]. The fluorescence images were taken on Day 5 by FDA staining method. For FDA staining $5 \mathrm{mg}$ of Flourescein diacetate [FDA] was mixed in $1 \mathrm{ml}$ of acetone and Propidium iodide [PI] [2mg/ml of PBS] was used. The growth medium from the 6-well plates to be stained were removed and a mixture of $5 \mathrm{ml}$ of fresh growth medium and $8 \mu \mathrm{L}$ of FDA solution along with $50 \mu \mathrm{L}$ of PI solution was added to each well containing the material on which the cells are adhered. Then the plate is incubated for 5 minutes in dark before imaging it with fluorescent microscope (Figure 17). The images showed better adherence of $3 \mathrm{~T} 3[\mathrm{NIH}]$ cells on the surface of propolis incorporated material (Figure $17 \mathrm{~b}$ ) however the rate of proliferation of the material without propolis extracts was slightly higher (Figure 18) than the cellulose composite 
with propolis. Papain [80 $\mu \mathrm{g} / \mathrm{ml}$ for 5 minutes] [41] was used with PBS as dissociation medium. The entire study was performed in an ethical way using animal cruelty-free reagents as alternatives to fetal bovine serum and trypsin. It was noted that the cell viability has increased significantly and the proliferation rate was consistent. This shows that the materials are non-toxic and biocompatible [Figure $17 \& 18$ ]. $2 \%$ antibiotic was used in the culture medium. Human blood serum was filtered with $0.45 \mu \mathrm{m}$ syringe filter each time before use. After 24 hours and 120 hours, $50 \mu \mathrm{L}$ of MTT $[0.05 \mathrm{mg} / \mathrm{ml}$ of Phosphate buffer solution] was added to each well in the 96 well plate and was allowed to incubate for 3 hours at $37^{\circ} \mathrm{C}$, following which $150 \mu \mathrm{L}$ of DMSO was added to it and incubated for 15 minutes in order to allow the living cells to convert tetrazole [yellow colour] into formazan [purple colour].

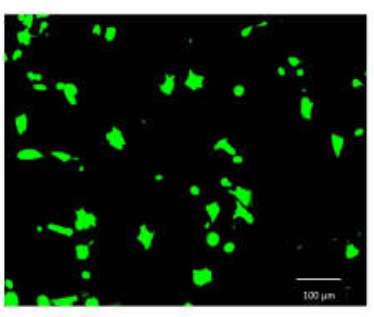

(a)

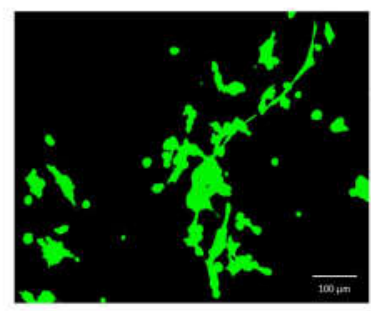

(b)
Figure 17: Fluorescent images of the 3T3 fibroblast cells attached and proliferating on the cellulose composite materials [a] without propolis [b] with propolis taken on Day 5

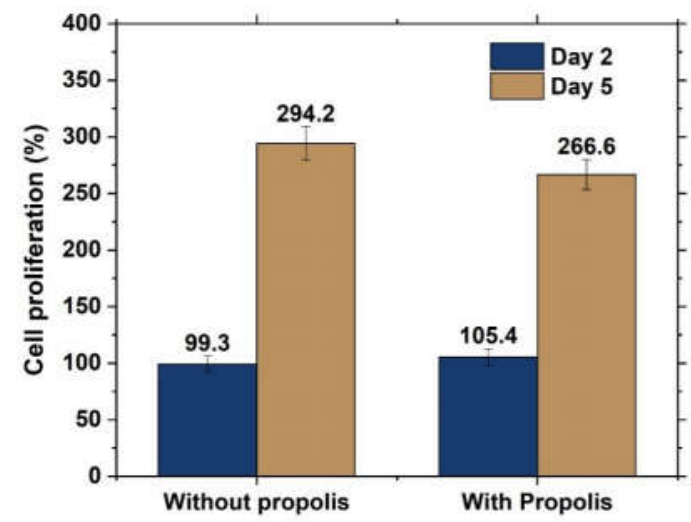

Figure 18: MTT assay results for the cellulose composite material for Day 2 \& Day 5

The absorbance of the viable cells was measured using a plate reader at $590 \mathrm{~nm}$ wavelength. The percentages of viable cells were calculated using the following formula.

$\%$ Viable cells

$=\left(\frac{O . D \text { of the sample }-O . D \text { of the negative control }}{O . D \text { of the positive control }-O . D \text { of the negative control }}\right) \times 100$

The present study was performed with cellulose composite material in cast film form because of the feasibility to perform various nanomechanical and other physical characterization such as folding endurance, contact angle and oxygen permeability tests, etc. The crystallinity of the polymer is higher with cast film than with the electrospun fibers due to the slow evaporation process used for forming the films. Hence the method of synthesis may have some effect on thermal degradation, surface morphology and in the mechanical properties of the material[42].

\section{Conclusions}

On account of choosing the right alternative for natural resorbable suturing, focus on cruelty-free alternative material that suits the requirements for an efficient suture material, cellulose acetate composite material was thus synthesized for its capability to withstand heat sterilization temperatures. The material was experimented for its physico-chemical properties, biological properties such as anti-bacterial efficiency, hemocompatibility, biocompatibility and thrombogenicity. The material was analyzed in detail for its drug delivery property. The addition of propolis extracts [a natural defense mechanism used by honey bees to protect their hive] with the cellulose composite has given a sustained drug release property. The addition of lipophilic propolis extract has also given the material an ideal surface wettability property in order to reduce the friction between the suture and the tissue in contact. Also, it has greatly improved the mechanical strength of the material. The material's flexibility can be ascribed to the presence of glycerol triacetate and diethyl phthalate in the composite. The addition of propolis extracts has improved the composite's properties in such a way to suit the requirement for an ideal suturing material.Propolis incorporation has given a sustained release profile for the material of about $56.96 \%$ drug released in 72 hours whereas for the material without propolis the release percentage was calculated as $100 \%$ for 72 hours. The invitro degradation study which was carried out in DMEM medium showed a slow degradation of the composite materials $[36.7 \%$ for without propolis and $37.5 \%$ for with propolis incorporation] in 90 days which makes it suitable for slow healing tissues. the degradation results were backed with significant changes of the materials' mechanical property and the surface morphology. The contact angle was found to increase [57.4 ${ }^{\circ}$ ] significantly upon incorporation of propolis extract. The addition of aromatic rings rich propolis extract to the structurally and mechanically strong cellulose acetate/HPMC/PEO composite material has enhanced the material in all aspects suitable for an ideal suture application.

\section{Acknowledgement}

We thank DST- Women's Scientist Scheme-A for providing funding for the work. We also thank Dr. Raghunandhakumar Subramanian and Dr.K. Pavani of Centre for Biotechnology, Anna University, Chennai for supplying us with cell lines to carry out the cytotoxicity test. we sincerely thank Prof. R. Jayavel of Centre for Nanoscience and Nanotechnology, Anna University for the SEM images.

\section{References}

1. Pillai CKS, Sharma CP. Review paper: Absorbable polymeric surgical sutures: Chemistry, production, properties, biodegradability, and performance. Vol. 25, Journal of Biomaterials Applications. 2010.

2. Planck H. General Aspects in the Use of Medical Textiles for Implantation. In: Medical Textiles for Implantation. 1990.

3. Banche G, Roana J, Mandras N, Amasio M, Gallesio C, Allizond $\mathrm{V}$, et al. Microbial Adherence on Various Intraoral Suture Materials in Patients Undergoing Dental Surgery. J Oral Maxillofac Surg. 2007;65[8]. 
4. Leknes KN, Røynstrand IT, Selvig KA. Human Gingival Tissue Reactions to Silk and Expanded Polytetrafluoroethylene Sutures. J Periodontol. 2005;76[1].

5. Abi Rached RS, de Toledo BE, Okamoto T, Marcantonio Júnior E, Sampaio JE, Orrico SR, et al. Reaction of the human gingival tissue to different suture materials used in periodontal surgery. Braz Dent J. 1992;2[2].

6. Osada Y, Gong JP, Tanaka Y. Polymer Gels. Vol. 44, Journal of Macromolecular Science - Polymer Reviews. 2004.

7. Charbit Y, Hitzig C, Bolla M, Bitton C, Bertrand MF. Comparative study of physical properties of three suture materials: Silk, e-PTFE [Gore-Tex]®, and PLA/PGA [Vicryl]®. Biomed Instrum Technol. 1999;33[1].

8. Chu CC. Biodegradation Properties. In: Wound Closure Biomaterials and Devices. 2018.

9. Singhal JP, Singh H, Ray AR. Absorbable suture materials: Preparation and properties. J Macromol Sci - Rev Macromol Chem Phys. 1988;C28[3-4].

10. MOY RL, WALDMAN B, HEIN DW. A Review of Sutures and Suturing Techniques. J Dermatol Surg Oncol. 1992;18[9].

11. Horacek I. Survey of the present knowledge on biodegradable polymers for resorbable sutures. Vol. 39, Chemicke Vlakna. 1989.

12. Hon LQ, Ganeshan A, Thomas SM, Warakaulle D, Jagdish J, Uberoi R. Vascular Closure Devices: A Comparative Overview. Vol. 38, Current Problems in Diagnostic Radiology. 2009.

13. Yu G V., Cavaliere R. Suture materials. Properties and uses. J Am Podiatry Assoc. 1983;73[2].

14. Bennett RG. Selection of wound closure materials. J Am Acad Dermatol. 1988;18[4].

15. BINNEY H. Claudius' Iodized Catgut. Bost Med Surg J. $1904 ; 150[19]$.

16. ADONI A, ANTEBY E. The use of Histoacryl for episiotomy repair. BJOG An Int J Obstet Gynaecol. 1991;98[5].

17. Awadein A, Sharma M, Bazemore MG, Saeed HA, Guyton DL. Adjustable suture strabismus surgery in infants and children. J AAPOS. 2008;12 [6].

18. Pillai CKS, Sharma CP. Review paper: Absorbable polymeric surgical sutures: Chemistry, production, properties, biodegradability, and performance. J Biomater Appl. 2010;25[4]:291-366.

19. Francoeur JR. Joseph Lister: Surgeon scientist [1827-1912]. Vol. 13, Journal of Investigative Surgery. 2000.

20. LAWRIE P, ANGUS GE, REESE AJ. The absorption of surgical catgut. Br J Surg. 1959;46.

21. Bernal-Ballén A, Kuritka I, Saha P. Preparation and Characterization of a Bioartificial Polymeric Material: Bilayer of Cellulose Acetate-PVA. Int J Polym Sci. 2016;2016.

22. Sill TJ, Von Recum HA. Electrospun materials for affinitybased engineering and drug delivery. In: Journal of Physics: Conference Series. 2015.

23. Ramadoss P, Subha V. A comparitive study of drug release profile of propolis and diclofenac for efficient wound healing. 2015;6[6]:69-74.

24. Baygar T. Characterization of silk sutures coated with propolis and biogenic silver nanoparticles [AgNPs]; an ecofriendly solution with wound healing potential against surgical site infections [SSIs]. Turkish J Med Sci. 2020;50[1].

25. Zhao G, Zinger O, Schwartz Z, Wieland M, Landolt D, Boyan BD. Osteoblast-like cells are sensitive to submicron-scale surface structure. Clin Oral Implants Res. 2006;17[3].

26. Yunita RF, Student PG. Manufacturing \& Characterization of Cellulose Acetate Film from Oil Palm Logs [ Elaeis Guinensis Jack ] with Chloroform as Solvent \& Triacetin as Plasticizer. 2018;4[8]:86-91.

27. De Carvalho Eufrásio Pinto $M$, David Da Silva D, Amorim Gomes AL, Leite V dos SA, Fialho E Moraes AR, Ferreira de Novais R, et al. Film based on magnesium impregnated biochar/cellulose acetate for phosphorus adsorption from aqueous solution. RSC Adv. 2019;9[10].

28. Muffly TM, Tizzano AP, Walters MD. The history and evolution of sutures in pelvic surgery. Vol. 104, Journal of the Royal Society of Medicine. 2011.
29. Agalloco JP, Akers JE, Madsen RE. Moist heat sterilization Myths and realities. Vol. 52, PDA Journal of Pharmaceutical Science and Technology. 1998.

30. Zhang G, Zheng G, Ren T, Zeng X, van der Heide E. Dopamine hydrochloride and carboxymethyl chitosan coatings for multifilament surgical suture and their influence on friction during sliding contact with skin substitute. Friction. 2020;8[1].

31. Ritchie TJ, MacDonald SJF, Young RJ, Pickett SD. The impact of aromatic ring count on compound developability: Further insights by examining carbo- and hetero-aromatic and aliphatic ring types. Vol. 16, Drug Discovery Today. 2011.

32. Ramadoss $P$, Thanigai Arul K, Ramana Ramya J, Rigana Begam M, Sarath Chandra V, Manikandan E. Enhanced mechanical strength and sustained drug release of gelatin/keratin scaffolds. Mater Lett [Internet]. 2017;186:109-12. Available from: http://dx.doi.org/10.1016/j.matlet.2016.09.095

33. S S, K A, T P, Reddy P S, G S, R N, et al. Fabrication of Surgical Sutures Coated with Curcumin Loaded Gold Nanoparticles. Pharm Anal Acta. 2017;08[01].

34. Mishra A, Chaudhary N. Study of povidone iodine loaded hydrogels as wound dressing material. Trends Biomater Artif Organs. 2010;23[3]:122-8.

35. Pittarate C, Yoovidhya $\mathrm{T}$, Srichumpuang $\mathrm{W}$, Intasanta $\mathrm{N}$, Wongsasulak S. Effects of poly[ethylene oxide] and $\mathrm{ZnO}$ nanoparticles on the morphology, tensile and thermal properties of cellulose acetate nanocomposite fibrous film. Polym J. 2011;43[12].

36. Tsiapla AR, Karagkiozaki V, Bakola V, Pappa F, Gkertsiou P, Pavlidou E, et al. Biomimetic and biodegradable cellulose acetate scaffolds loaded with dexamethasone for bone implants. Beilstein J Nanotechnol. 2018;9[1]:1986-94.

37. García-Vargas M, González-Chomón C, Magariños $B$, Concheiro A, Alvarez-Lorenzo C, Bucio E. Acrylic polymergrafted polypropylene sutures for covalent immobilization or reversible adsorption of vancomycin. Int J Pharm. 2014;461[1-2].

38. Weldon CB, Tsui JH, Shankarappa SA, Nguyen VT, Ma M, Anderson DG, et al. Electrospun drug-eluting sutures for local anesthesia. J Control Release. 2012;161[3].

39. Arora A, Aggarwal G, Chander J, Maman P, Nagpal M. Drug eluting sutures: A recent update. J Appl Pharm Sci. 2019;9[7]

40. Dash S, Murthy PN, Nath L, Chowdhury P. Kinetic modeling on drug release from controlled drug delivery systems. Vol. 67, Acta Poloniae Pharmaceutica - Drug Research. 2010.

41. Noviantari A, Novianti R, Rinendyaputri R. Comparison of dissociation capability of papain [Carica papaya L.] and trypsin on rat bone marrow mesenchymal stem cells [rBMMSCs] culture [preliminary study]. In: AIP Conference Proceedings. 2019.

42. Ghosal K, Chandra A, Praveen G, Snigdha S, Roy S, Agatemor $\mathrm{C}$, et al. Electrospinning over Solvent Casting: Tuning of Mechanical Properties of Membranes. Sci Rep [Internet]. 2018;8[1]:1-9. Available http://dx.doi.org/10.1038/s41598-018-23378-3 